\title{
The Effect of Demographic Variables on Secondary Level Students' Attitude towards Mathematics in Nepal
}

\author{
Rajendra Kunwar \\ Associate Professor, Mathematics Education, Mahendra Ratna Multiple Campus, Ilam, \\ Tribhuvan University, Nepal, Email: rajendrailam@gmail.com
}

\begin{abstract}
Student's attitude towards mathematics is a global issue that directly influences the students' achievement in mathematics. The study aimed at investigating the students' attitudes towards mathematics and the effects of demographic variables on their attitude in the selected grade IX Students in Provence No 1, Nepal. The study has adopted a quantitative survey design. A total of 540 grade IX students were selected randomly and the revised attitude scale ATMI of Tapia and Marsh (2004) was adopted to find out their attitudes towards mathematics and the effect of demographic variables. The data were analyzed using mean, standard deviation, and multiple linear regressions. The results of the study showed that the students' attitude towards mathematics is positive. Similarly, the effects of students' attitudes towards mathematics in terms of demographic variables (age, gender, family type, parent's education, parent's occupation, school location, and ecological region) were found low. The attitude of the students at a different age level showed a greater decline in attitudes as the students increase their grade level. However, the results showed that other considerable variables may have more impact on students' attitudes towards mathematics.
\end{abstract}

Keywords: ATMI, Demographic variables, Mathematics, Secondary level, Student's attitude

\section{Introduction}

\section{Meaning and Definition of Attitude}

Attitude is the manner, disposition, feeling, or position with regard to a person, things, or events. It can be referred to as a person's viewpoint, mindset, or beliefs towards a person, places, things, or situations. The word 'attitude' stems from the Latin word 'aplus' meaning fitness or adaption. It is the mental state of preparation for action. The construct 'attitude' has originated from the field of social psychology (Allport, 1935). The study of attitudes toward mathematics has given special attention due to its crucial role in the learning of mathematics (Neale, 1969). Attitudes reflect the overall evaluations of persons, groups, objects, and events in the social world and help to make the decision. Attitudes are important because they affect both the way we perceive the world and how we behave. However, the formal definitions of attitude vary according to their focus given by the social psychologists on the attribute of 
attitude (Bem, 1970; Fishbein \& Ajzen, 1975; Eagly \& Chaiken 1993). Attitude refers to a set of emotions, beliefs, and behaviors toward a particular person, object, thing, or event. Attitudes are often the result of experience, learning, conditioning, observation, and social factors and can have a great influence over behavior.

The definition of attitude became broader gradually as time passes over and the different social psychologists interpret the meaning of attitude relating to multiple dimensions. Attitudes are not innate but result from environment and experiences and can be changed over time. Attitudes are global issues and are the consequences of different incidence. Koballa (1988) has affirmed the three common disposition of attitude as i) Attitudes are enduring and seem to remain relatively stable over time. ii) Attitudes are learned or acquired. iii) Attitudes are related to a person's behavior, that is, students' actions reflect their feelings toward objects and issues. As stated by Mohamed and Waheed (2011), student attitudes can be influenced by three groups of factors. The factors associated with the students themselves (mathematical achievement, anxiety, self-efficacy and self-concept, motivation, and experiences at school, etc.), factors associated with the school teacher and teaching (teaching materials, classroom management, teacher knowledge, attitudes towards mathematics, guidance, beliefs, etc.) and factors related to home environment and society(educational background, parental expectations, socio-economic status, parental education, etc.).

In the beginning, Allport (1947) introduced attitude as a classic definition (one dimensional) "mental and neural state of readiness, organized through experiences, exerting a direct or dynamic influence upon the individual's response to all objects and situations with which it is related". However, in recent times, it is considered as the combination of three components affect, cognition, and behavior (Gall et al., 2007; Syyeda, 2016). The affective component is composed of emotions and beliefs about the attitude object. Emotions are the pleasure feelings of enjoyment in learning or bore feeling or difficult. Beliefs are the students' confidence in their abilities to learn the subject. Cognition or the cognitive component refers to an individual's beliefs or knowledge about the object, thoughts, and attributes that associate with a particular object. Similarly, behavior or the behavioral component is concerned with student's actions, commitment, and performance. It also refers to past behaviors with regard to an attitude object. It is connected to students' motivation to learn, act, and perform the task.

\section{Defining Attitude toward Mathematics}

The definition of attitude can mainly be categorized into three types according to the degree of the affect associated with a certain subject. The first type of definition of attitude that describes a one-dimensional aspect of attitude as the positive or negative degree of affect (emotion, feeling) associated with a certain subject (Haladyna et al., 1983). This definition suggests the definition of attitude toward mathematics just as a positive or negative emotional 
disposition toward mathematics (McLeod, 1992). The second type of definition explores the bidimensional aspects of attitude that comprise emotional response and beliefs regarding mathematics (Daskalogianni \& Simpson, 2000). The third type of definition explores the multidimensional (tripartite) aspects of attitude that consists of emotional response towards mathematics, beliefs regarding mathematics, and behavior related to mathematics (Hart, 1989; Di Martino and Zan, 2010; Syyeda (2016). The multi-dimensional definition of attitude toward mathematics is more complex in the sense of affects that associates with mathematics (which, however, have a positive or negative value), beliefs towards mathematics, and behaviors related to mathematics (Hart, 1989).

The simple definition of attitude as a positive or negative degree of affect or emotion toward mathematics means the positive attitude is a positive emotional disposition toward the subject and the negative attitude is a negative emotional disposition toward the subject. Meaning of the different three aspects of attitudes (affect, belief and behavior) relating to mathematics, affect refers to both emotions and feeling either positive or negative that depends on the situation perceived as pleasurable or anxious towards the subject. Belief generally refers to the facts shared by experts. Positive belief means that it is supposed to elicit a positive emotion towards mathematics that may be positive or successful behavior towards mathematics. Beliefs are often used to assess the significance of the emotional dimension. Similarly, behavior refers to positive generally means successful behavior, in the school context, successful behavior is generally referred to as high achievement. Similarly, a negative behavior reduces desired actions, in the school context, the learners' engagement in learning mathematics decrease, and thus the achievement level also becomes low. The problem related to teaching and learning mathematics is a worldwide issue that many of the countries are facing the problem of poor performance in mathematics, failure in mathematics, and difficulty in understanding of basic concepts of mathematics (Ramanujam, Sachdev \& Subramanian, 2007; Singha et al., 2012).

\section{Context of the Study}

Mathematics has been placed as a fundamental part of the school curriculum from the beginning of the formal school education system in Nepal. It is still taken as one of the core subjects upto grade $\mathrm{X}$ at the Secondary Level curricula. Despite the priority given to mathematics, a huge mass of students are struggling to understand the subject (Mazana, Montero, \& Casmir, 2020). The result of the students at school level examination and Secondary Education Examination (SEE) in mathematics has been reflecting a very pitiable situation (NASA, 2019). Most of the students consider the subject as a very difficult subject to study (Capuno et al., 2019). The perception of the students "mathematics as a difficult subject" is one of the major issues" that persist them to develop a negative attitude towards mathematics and consequently, they tend to dislike the subject (Kunwar, 2020). As stated by Mutai (2011), 
"once a positive attitude is formed, it can improve students' learning". Different teaching activities utilizing proper materials help the learner to explore or learn and to stimulate interest and develop a positive attitude towards learning mathematics (Kunwar, 2020). Such teaching makes mathematics learning more interesting, quicker, and easy.

Despite continual efforts to achieve the curricular goals, mathematics achievements in school-level education are still at a poor level in Nepal (Mahato, Morgan \& Earnest, 2019; NASA, 2019). As shown by the report, NASA (2019), only $29 \%$ of the students having adequate knowledge and skills in mathematics indicate a huge mass of students is at the underperforming level in mathematics. The reasons behind such poor achievement in mathematics may have different causes, however; students' attitudes towards the subject have a greater impact on academic achievements (Peteros et al., 2019). Thus, the scenario of the students' mathematics achievement at the school level demands further investigation about the status of students' attitudes towards mathematics.

\section{Significance of the Study}

Students attitude towards mathematic is a worldwide issue. Attitude is one of the major factors affecting the students' mathematics performance (Mohd et al., 2011; Capuno et al., 2019) Since, the students' behavior is the consequence of their attitude (Ratanasiripong \& Chai, 2013), implies students learning depends upon their attitude. This consequence shows a strong relationship between attitude and behavior and thus is necessary to create a positive attitude towards learning mathematics to the students for higher achievement in mathematics. In contrary to this, attitude follows behavior (Bem, 1972) asserts that attitude is the main cause for behavior as 'Happy people smile'. This also confirms the importance of students' attitudes toward learning mathematics. Thus students' attitude towards mathematics is an important predictor of students' achievement in mathematics.

This study aims to find out the school level students' attitudes toward mathematics relating to their demographic variables, such as age, gender, ecological region, and place of residence, and school type. It provides significant information about the effect of students' demographic variables on their attitude toward mathematics. The study reveals the existing effects of the attitude toward mathematics in relation to their demographic variables. Thus, it contributes to the current knowledge regarding students' attitudes towards learning mathematics at the school level and helps to create students' positive attitudes towards mathematics. It can help to find some solutions to mitigate the impact of the demographic variables on the students' attitudes towards mathematics. This study helps to create positive attitudes towards mathematics in terms of demographic variables. It also helps to promote the student's levels of mathematics achievement. Thus, this study might contribute effectively to the understanding of the student's attitude towards mathematics at the secondary level and its 
relationships with the demographic variables. Moreover, it may also help to promote a positive attitude by implementing innovative methods in teaching mathematics.

\section{Objectives of the Study}

The research study attempts to investigate the following objectives:

i) to find out the secondary level students' attitudes towards mathematics in Nepal;

ii) to examine the relationships of the demographic variables (age, gender, family type, parents education, parents occupation, school location, and ecological region) on students attitude towards mathematics;

iii) to investigate the effect of demographic variables (age, gender, family type, parents education, parents occupation, school location, and ecological region) on students attitude towards mathematics;

\section{Methodology}

\section{Research Design}

The study has adopted a quantitative survey design to investigate the students' attitudes towards mathematics at the secondary level. This study helps to determine the students' beliefs, feelings, and behaviors towards learning mathematics and also find out the relationships between the demographic variables. As stated by Gay, Mills, and Airasian (2012), survey research involves testing hypotheses regarding students' attitudes, behaviors, opinions, and perceptions of the students about a certain object or phenomenon through collecting data.

\section{Population}

The population of this study consisted of the students who are studying at grade IX, secondary schools, located in Province No. 1, Nepal. The students who have passed class eight and enrolled in class nine in $2076 \mathrm{~B}$. S. were considered as the population. The population of the study contained 14- 19 years of age groups including the different demographic backgrounds.

\section{Sample and Sampling Procedure}

This study utilizes the multistage sampling procedure considering the great variation in geographic structures, languages, ethnic groups, religions, culture, and occupation of Nepal. In the beginning, the whole population was divided into non-overlapping strata incorporating the three ecological regions the Hill, the Mountain, and the Terai. All the districts of Province No. 1 are categorized into three ecological regions according to the 'Local Government Operation Act 2074, Government of Nepal'. Thus the strata were grouped with districts concerning the ecological region containing in each stratum, and from each stratum, two districts were selected 
randomly. In the second stage, the lists of secondary schools from the selected districts were made and also grouped the schools by urban and rural location. Finally, from each district, two schools, each one from the rural and urban list were selected randomly. In this way, six districts out of 14 from Province No. 1 containing two districts from each ecological region, namely, Panchthar and Okhaldhunga districts (from the Hill region), Taplejung and Solukhumbhu districts(from the Mountain region), and Jhapa and Sunsari districts(from the Terai region) were chosen. The sample of any study should represent the characteristics of the whole population under study. Thus while determining the sample size, it should be cautious.

\section{Sample Size Determination}

The sample size determination is extremely necessary while studying the human attributes located with a great variation in geographical, physical, social, cultural, and occupational aspects. The population for the study also has tremendous geographic diversity and altitude variation. Thus the sample size determination is necessary for this study. For the finite population, sample size can be calculated by using the formula given by Yamane (1967) i.e. $\frac{\mathrm{N}}{1+\mathrm{N}(\mathrm{e})^{2}}$ where $\mathrm{N}$ is the population size and $\mathrm{e}$ is the sampling error. If the sample size is calculated at the confidence level of $95 \%$ with a sampling error equal to (0.05), then the sample size becomes $\frac{57089}{1+57089(0.05)^{2}}=398$. So, for this study, the representative sample size can be taken 398. In the same way, as stated by Yamane (1967) and Glenn (1992), when the population is greater than 100,000 then the sample size will be 400 at a $95 \%$ confidence level. Hence, the sample $(n)=400$ can be considered appropriate for the study. In this study, 12 secondary schools from six districts containing each two from the Hills, the Mountains, and the Terai were chosen by using a random sampling technique. While selecting the schools from each district, one school from the municipal area and other schools from the rural municipal area were selected. Since the sample size for the study utilizing the theory of sample size determination is 398; however, this study exploits the sample size $(n)=540$ for the study selected 45 students of grade IX equally from each 12 sampled school.

\section{Instrumentation}

In this study, the instrument, revised attitude scale ATMI of Tapia, and Marsh (2004) was adopted. The instrument consists of two sections. The first section comprises the demographic information and the second section consists of adapted 40 ATMI Likert-type attitude items. The scale consists of 40-items, 5-points Likert scale ranging from strongly disagree to strongly agree namely, Strongly Disagree (SD), Disagree (D), Not Sure (N), Agree (A), and Strongly Agree (SA) ranging from 1 to 5. This construct measures four factors related to attitudes towards mathematics including self-confidence, value, enjoyment, and motivation. Where, self-confidence is defined as students' confidence and self-concept of their performance in mathematics. Self-confidence in mathematics refers to student perceptions of self as a 
mathematics learner that include beliefs about one's own ability to learn and perform well in mathematics (Adelson \& McCoach, 2011). The second factor on the ATMI, value, measures students' beliefs of the usefulness, relevance, and worth of mathematics in their daily life. The third factor, enjoyment refers to students' enjoyment in doing and learning mathematics (Kupari \& Nissinen, 2013). Student's enjoyment influences their behavior or cognitive aspect of attitude (Syyeda, 2016).The last factor, motivation is related to both interest and the desire to learn mathematics (Guy, Cornick \& Beckford, 2015). It provides a source of energy that helps the learner to make a continuous effort to sustain an activity. It is also considered as the driving force for learning (Yunus \& Ali, 2009).

The Attitudes towards Mathematics Inventory (ATMI) (Tapia \& Marsh, 2004) is one of the latest instruments, but it has not enjoyed significant application in research (Chamberlin, 2010). It was chosen for this study because it provides a sharp and distinct focus and identifies four dimensions along which attitudes toward mathematics could be measured. To ensure the relevancy and practicability of the questionnaire culturally and contextually, the ATMI questionnaire was translated into Nepali so that the students would better understand the terms used in ATMI and it was piloted in two schools of Ilam district, one from urban areas and the other from rural areas. The students were asked about some feedback and comments during the test regarding difficult terms and language then some ambiguity and difficulty were modified in the final version. The reliability of ATMI was calculated and found to be 0.86 .

\section{Data Collection Procedures}

The data related to students' attitudes towards mathematics were collected using the instrument to the sampled students from the selected schools using the ATMI scale adapted from Tapia \& Marsh (2004) with necessary validation in the context of Nepal. In this course, at first, permission from the school authority was taken before administering the survey instrument. Similarly, the participants were informed about the purpose and nature of the study and their voluntary participation. They were also guaranteed the complete anonymity of their response. While administering the ATMI in the classrooms, assistance from the mathematics class teacher was taken. The test administration was held during break time.

\section{Data Analysis}

The data obtained from the survey instrument, ATMI was analyzed using SPSS 23.0. In the beginning, a brief description of the participants is presented. The data were analyzed using descriptive as well as inferential statistics. The descriptive statistics included, means, standard deviations, and inferential statistics, multiple linear regression was used to analyze the data. At this point, negative items were scored in the reverse order. Mean scores were calculated for each statement of attitude aspect to get variables that were used in subsequent analysis. 


\section{Results}

\section{The Demographic Description of the Sample}

In this study, the secondary level students studying in grade IX were chosen as the informants considering age, gender, religions, parent's occupations, parent's education ethnicity, and types of family and school location. Thus, a total of 540 students from 12 different secondary schools were chosen for the study purpose. Among them, the number of male students was 72, 70, and 69 from the Mountains, the Hills, and the Terai respectively. Similarly, female students were selected 108, 110, \& 111 from the Mountains, the Hills, and the Terai respectively. In the same way, the number of male students in urban areas was 107 and that of the female students was 163. Likewise, male students in rural areas were 104, and female students were 166 . This scenario of gender distribution in the study by the ecological region and school location of the informant shows those, a greater number of participants have participated from the female category. Similarly, the distributions of the demographic variables are presented in Table 1.

\section{Table 1}

Demographics Distribution of the Sample

\begin{tabular}{|c|c|c|c|c|c|c|c|c|c|c|c|}
\hline \multirow[b]{2}{*}{ Demography } & \multirow{2}{*}{$\begin{array}{l}\text { Ecological Region } \\
\text { Category }\end{array}$} & \multicolumn{3}{|c|}{ Mountain Region } & \multicolumn{2}{|c|}{ Hill Region } & \multicolumn{4}{|c|}{ Terai Region } & \multirow[t]{2}{*}{ Subtota } \\
\hline & & Urban & Rural & Total & Urban & Rural & Total & Urban & Rural & Total & \\
\hline \multirow[t]{3}{*}{$\overline{\text { Age }}$} & $(14-15) Y r s$ & 55 & 67 & 122 & 60 & 56 & 116 & 42 & 43 & 85 & 323 \\
\hline & (16-17)Yrs & 31 & 22 & 53 & 29 & 29 & 58 & 45 & 41 & 86 & 197 \\
\hline & (18-19)Yrs & 4 & 1 & 5 & 1 & 5 & 6 & 3 & 6 & 9 & 20 \\
\hline \multirow[t]{2}{*}{ Gender } & Male & 39 & 37 & 76 & 40 & 34 & 74 & 36 & 38 & 74 & 211 \\
\hline & Female & 52 & 52 & 104 & 51 & 55 & 106 & 55 & 51 & 106 & 316 \\
\hline Parents & Agriculture & 65 & 73 & 138 & 62 & 65 & 127 & 60 & 53 & 113 & 378 \\
\hline \multirow{4}{*}{ Occupations } & Business & 12 & 9 & 21 & 9 & 14 & 23 & 6 & 0 & 6 & 50 \\
\hline & Government job & 4 & 5 & 9 & 11 & 5 & 16 & 13 & 21 & 34 & 59 \\
\hline & Foreign Employ & 3 & 2 & 5 & 4 & 2 & 6 & 9 & 11 & 20 & 31 \\
\hline & Others & 6 & 1 & 7 & 4 & 4 & 8 & 2 & 5 & 7 & 22 \\
\hline Parents & Illiterate & 19 & 39 & 58 & 8 & 3 & 11 & 11 & 6 & 17 & 86 \\
\hline \multirow[t]{3}{*}{ Education } & Basic & 59 & 32 & 91 & 75 & 85 & 160 & 53 & 46 & 99 & 350 \\
\hline & Secondary & 11 & 17 & 28 & 7 & 2 & 9 & 16 & 11 & 27 & 64 \\
\hline & Higher Education & 1 & 2 & 3 & 0 & 0 & 0 & 10 & 27 & 37 & 40 \\
\hline Types of & Joint & 52 & 54 & 106 & 68 & 58 & 126 & 53 & 81 & 134 & 366 \\
\hline Family & Nuclear & 38 & 36 & 74 & 22 & 32 & 54 & 37 & 9 & 46 & 174 \\
\hline
\end{tabular}

\section{Students' ATMI Interpretation Level}

The students' scores on different factors of ATMI with their demographic variables were compared and interpreted with the help of the ATMI interpretation level adapted from Andamon \& Tan (2018). The students' responses based on the 5 points Likert-type scale, were classified into five categories based on the range of the score of the students. Table 2 shows the number of students, attitude level, and their corresponding range of interpretation. In this study, 
the range of negative and highly negative is considered as the negative level and the range of positive and highly positive is considered as a positive level.

\section{Table 2}

Mean Scores Interpretation for Students Attitude Level

\begin{tabular}{lll}
\hline Range of Mean Score & Qualitative Description & Attitude Level \\
\hline $1.00-1.49$ & Strongly Disagree & Highly negative \\
$1.50-2.49$ & Disagree & Negative \\
$2.50-3.49$ & Uncertain & Neutral \\
$3.50-4.49$ & Agree & Positive \\
$4.50-500$ & Strongly Agree & Highly Positive \\
\hline
\end{tabular}

\section{Descriptive Statistics of Students' Attitude towards Mathematics}

The descriptive statistics of the students' attitude towards mathematics through the four factors-ATMI Scale, the students' item wise mean scores and standard deviations, and the overall mean score and standard deviation of the factors are presented in Table 3. The ATMI Scale consists of 11 negative items, out of 40 . So the lowest possible score was 40 and the highest score was 200. The responses of the grade X students' attitudes towards mathematics through the ATMI scale were scored and tabulated.

The overall factorwise means scores of the students and their corresponding attitude level shows that the mean scores of the factors, i.e. value, enjoyment, and motivation, are at the positive attitude level with the scores (4.17), (4.00), and (3.68) respectively. This range of the mean scores shows that the students were most positive in the factor valuing mathematics and they were also positive in the factors enjoyment and motivation factors. The mean score of the factor i.e. self-confidence (3.28) lies on a neutral attitude level. This indicates that they were neither positive nor negative in the factor 'self-confident', which means they were not completely self-confident in mathematics.

The mean scores of the 25 items $(1,2,3,4,5,6,7,8,9,11,12,13,14,15,16,17,18,19$, $20,22,26,27,33,37, \& 38$ ) shows that most of the students were found at the positive attitude level. In 14 items $(21,23,24,25,28,29,30,31,32,34,35,36,39,40)$ the students were found at the neutral attitude level, and in one and only one item 10, the students were found at a low attitude level. This shows that the students' found to be positive in most of the items regarding attitude towards mathematics. The overall mean score of the students' attitudes towards mathematics was found to be positive with a score of 3.78. This shows that, on average, the mean score of all of the factors indicates that the students were positive towards mathematics. 
Table 3

Descriptive Statistics of Students' Attitudes towards Mathematics

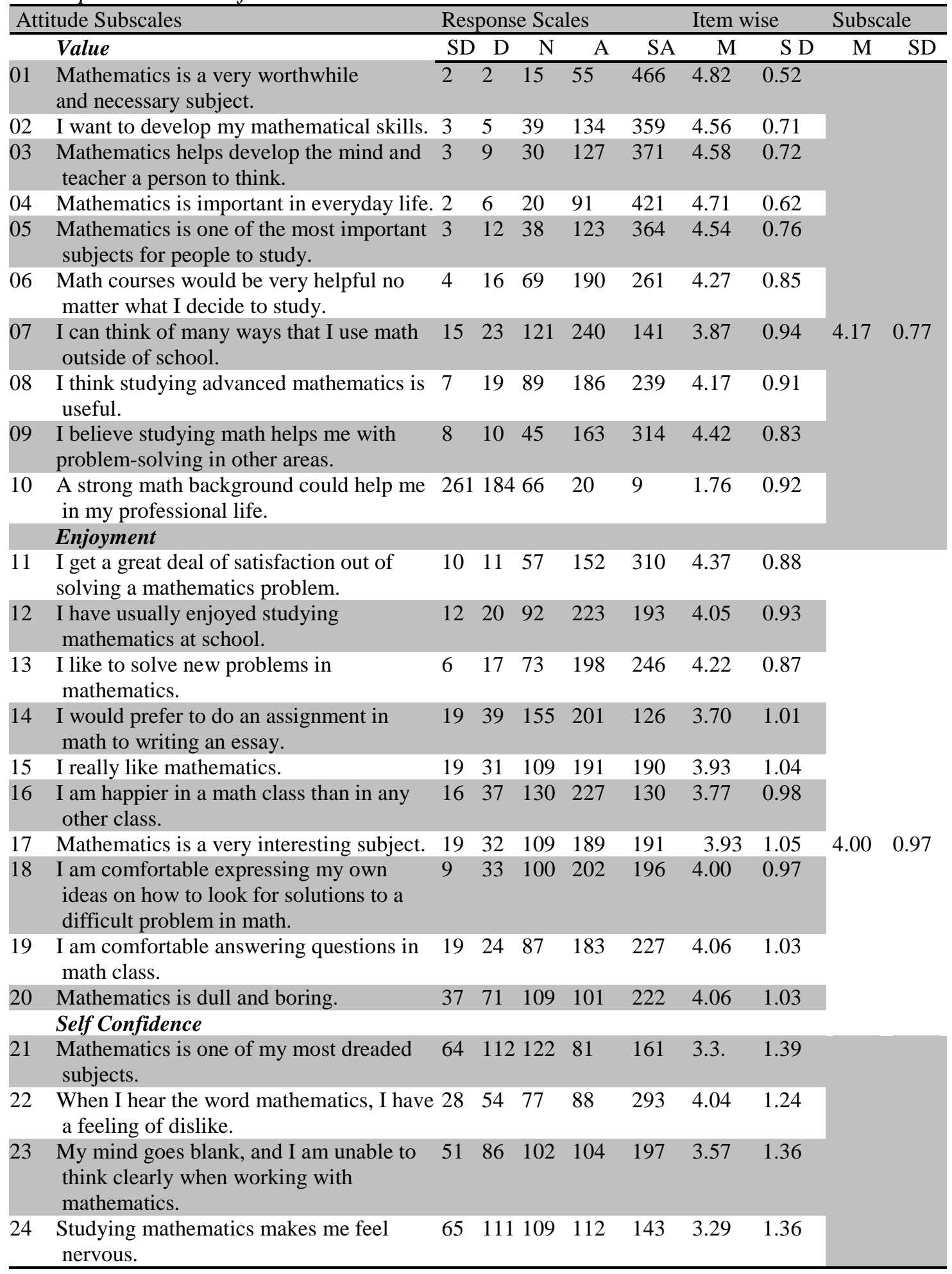




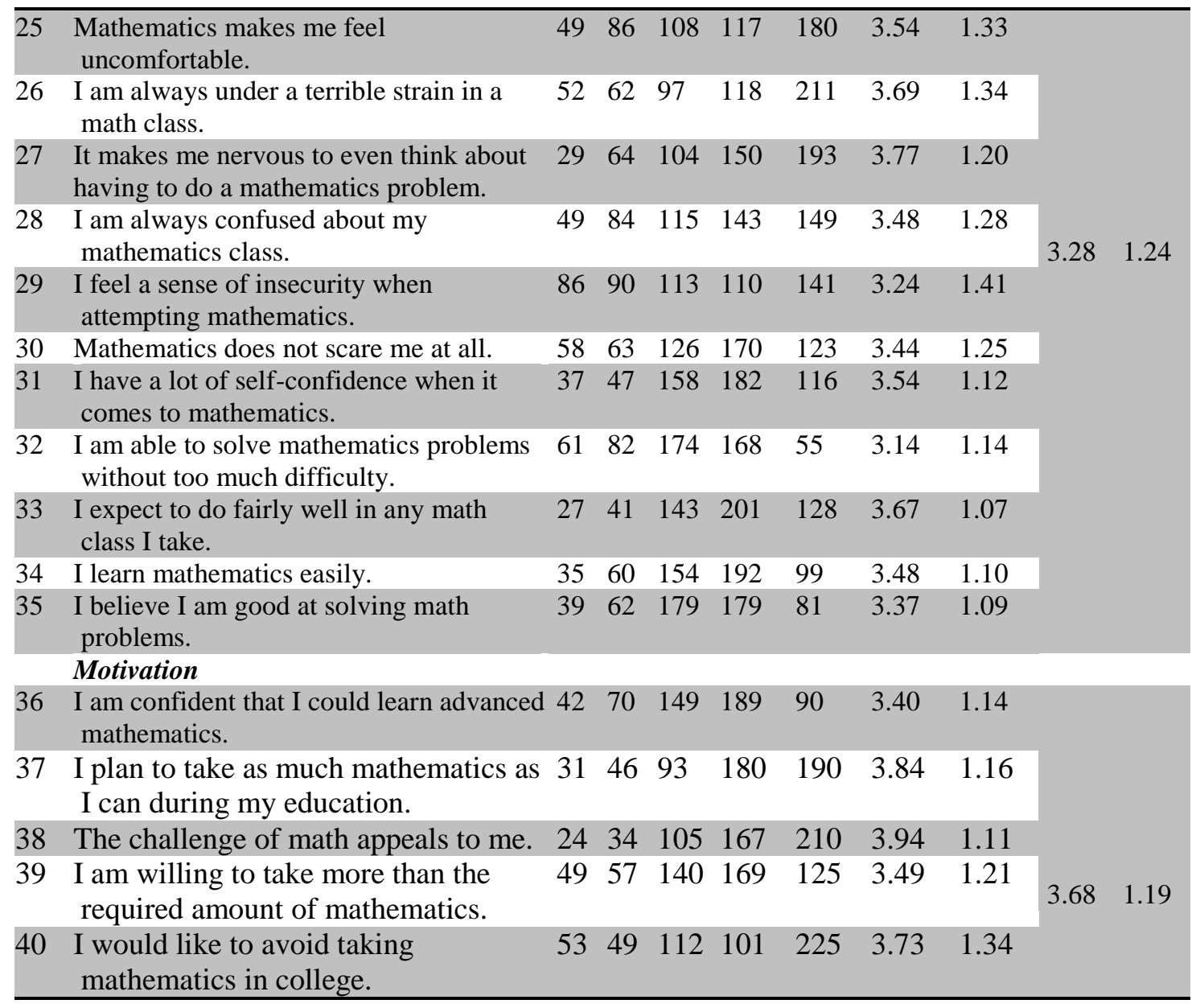

\section{Students' Attitude Level by Age}

The overall mean scores of the students' attitude level by age, as shown in Table 4, indicate that the students' attitude level at (14-15) yrs age group found 3.89 which is higher than the mean score of other age groups (16-17)yrs and (18-19)yrs. In the same way, the mean scores of each factor value, enjoyment, confidence, and motivation at (14-15) yrs age group are higher than the other age group. The overall and factor wise mean scores of the students' attitude level at (14-15)yrs age group lie at the positive attitude level. The factor wise or overall higher mean score(s) at (14-15) yrs of age group indicate that the students within the age (1415) yrs have more positive attitudes towards mathematics than the students of the other age group. The value of the standard deviation indicates that the data tend to be very close to the mean or are more concentrated on the mean. The overall mean scores at the (16-17) yrs and (18-19) yrs age groups were also found at a positive attitude level. This indicates that the students of all different age groups found to be a positive attitude towards mathematics however, the low-age students found more positive than high-age students among the age 
group. The standard deviations of the factors in the all age group are found to be moderate. This indicates that the data points are a normal range of values to the mean.

Table 4

Descriptive Statistics of the Students' Attitude Level by Age

\begin{tabular}{lcccccc}
\hline \multirow{2}{*}{ Attitude Levels } & \multicolumn{7}{c}{$(14-15)$ Yrs } & \multicolumn{2}{c}{$\begin{array}{c}\text { Age Group } \\
(16-17)\end{array}$} & Yrs & \multicolumn{2}{c}{$(18-19)$ Yrs } \\
\hline & $\mathrm{M}$ & $\mathrm{SD}$ & $\mathrm{M}$ & $\mathrm{SD}$ & $\mathrm{M}$ & $\mathrm{SD}$ \\
\cline { 2 - 7 } & 4.18 & 0.36 & 4.15 & 0.36 & 4.05 & 0.49 \\
Value & 4.06 & 0.62 & 3.84 & 0.60 & 3.50 & 0.64 \\
Enjoyment & 3.56 & 0.70 & 3.35 & 0.64 & 3.23 & 0.69 \\
Confidence & 3.76 & 0.76 & 3.50 & 0.78 & 3.23 & 0.69 \\
Motivation & 3.89 & 0.61 & 3.71 & 0.59 & 3.50 & 0.53 \\
Total & & & & & & \\
\hline
\end{tabular}

\section{Students' Attitude Level by Gender}

The overall mean scores of the students' attitude level by gender, in Table 5, i.e. the mean score of male (3.80) and female (3.83) indicates that there is no significant difference in students' attitudes towards mathematics by gender. The factor wise mean score of the students attitude towards mathematics also verify their similar attitude. The factor wise standard deviations of the male in confidence (1.22), motivation (1.18) and female in the factors, confidence (1.30), and motivation (1.19) found high. This indicates that the data points are spread out or scattered over a large range of values. This means that data related to students attitudes of both males and females are not in the uniform range of values to the mean. However, the overall and factor wise mean scores of both male and female lie at the positive attitude level.

\section{Table 5}

Descriptive Statistics of the Students' Attitude Level by Gender

\begin{tabular}{|c|c|c|c|c|}
\hline \multirow{3}{*}{ Attitude Levels } & \multicolumn{4}{|c|}{ Gender } \\
\hline & \multicolumn{2}{|c|}{ Male } & \multicolumn{2}{|c|}{ Female } \\
\hline & $\mathrm{M}$ & SD & $\mathrm{M}$ & SD \\
\hline Value & 4.14 & 0.69 & 4.18 & 0.67 \\
\hline Enjoyment & 3.99 & 0.98 & 3.89 & 0.98 \\
\hline Confidence & 3.53 & 1.22 & 3.50 & 1.30 \\
\hline Motivation & 3.56 & 1.18 & 3.75 & 1.19 \\
\hline Total & 3.80 & 1.01 & 3.82 & 1.03 \\
\hline
\end{tabular}

\section{Students' Attitude Level by Types of Family}

The overall mean scores of the students' attitude level by types of family shows that the mean score of the joint family (3.80) is higher than the mean score of the nuclear family (3.65) (Table 6). This indicates that the students from the joint family are comparatively more positive than the students from the nuclear family towards mathematics. The students from the joint family found more positive in the factor value (4.29), enjoyment (4.02), and confidence (3.56) in comparison to the factors of nuclear family, value (4.10), enjoyment (3.46), and confidence 
(3.37) respectively. The students of the joint family in the factor motivation (3.33) found neutral and the factors motivation (3.70) from nuclear family found more positive in comparison to the joint family. The factor-wise standard deviations of both families were found to be moderate. This indicates that the data points are a normal range of values to the mean.

Table 6

Descriptive Statistics of the Students' Attitude Level by Types of Family

\begin{tabular}{lcccc}
\hline \multirow{2}{*}{ Attitude Levels } & \multicolumn{2}{c}{ Toint Family } & \multicolumn{2}{c}{ Nuclear Family } \\
& $\mathrm{M}$ & $\mathrm{SD}$ & $\mathrm{M}$ & $\mathrm{SD}$ \\
\cline { 2 - 5 } Value & 4.29 & 0.35 & 4.10 & 0.41 \\
Enjoyment & 4.02 & 0.66 & 3.46 & 0.69 \\
Confidence & 3.56 & 0.67 & 3.37 & 0.77 \\
Motivation & 3.33 & 0.80 & 3.70 & 0.81 \\
Total & 3.80 & 0.62 & 3.65 & 0.67 \\
\hline
\end{tabular}

\section{Students' Attitude Level by Parental Education}

The students' attitude towards mathematics from the parent's education perspective, the overall mean scores of the students' attitude level of illiterate (3.37), basic (3.82), secondary (3.88), and higher education (3.90) were found (Table 7). This shows that the students were found more positive towards mathematics as they were from the higher educated family. Similarly, the mean score of the factor wise attitude level of the students towards mathematics was also found comparatively higher from the students who were from higher educated parents This indicates that the parents' education impacts their child's positive attitude towards mathematics. On the other hand, the factor wise standard deviations of the different level of parents' education found to be moderate. This indicates that the data points of the different categories of parent's education are at the normal range of values to the mean.

\section{Table 7}

Descriptive Statistics of the Students' Attitude Level by Parental Education

\begin{tabular}{lcccccccc}
\hline \multirow{2}{*}{ Attitude Levels } & \multicolumn{1}{c}{ Illiterate } & \multicolumn{3}{c}{ Basic(1-8) } & \multicolumn{2}{c}{ Secondary (1-12) } & \multicolumn{2}{c}{ Higher Education } \\
& $\mathrm{M}$ & $\mathrm{SD}$ & $\mathrm{M}$ & $\mathrm{SD}$ & $\mathrm{M}$ & $\mathrm{SD}$ & $\mathrm{M}$ & $\mathrm{SD}$ \\
\cline { 2 - 9 } & 4.10 & 0.41 & 4.17 & 0.37 & 4.21 & 0.33 & 4.21 & 0.40 \\
Value & 3.89 & 0.79 & 3.95 & 0.68 & 4.01 & 0.51 & 4.03 & 0.70 \\
Enjoyment & 3.44 & 0.78 & 3.48 & 0.70 & 3.60 & 0.65 & 3.62 & 0.72 \\
Confidence & 3.68 & 0.93 & 3.68 & 0.76 & 3.73 & 0.77 & 3.74 & 0.93 \\
Motivation & 3.77 & 0.72 & 3.82 & 0.62 & 3.88 & 0.56 & 3.90 & 0.68 \\
Total & & & & & & & & \\
\hline
\end{tabular}

\section{Students' Attitude Level by Parental Occupations}

The students' attitude towards mathematics with respect to their parent's occupation, the overall mean scores of the students' attitude level with regard to agriculture (3.31), business (3.87), government job (3.89), foreign employ (3.79 and others (3.80) were found at positive level(Table 8). Among these all attitude levels, the students' attitude towards mathematics having parents with government jobs were found to be comparatively more positive than the 
other students having parents with other occupations. Gradually, they were found less positive having the parents with occupations- business, agriculture, others, and foreign employ towards mathematics. This show that, the parents' occupation impact on students' attitude towards mathematics. Likewise, the factor-wise standard deviations of the different levels of parents' occupations were found to be moderate and hence the data points of the different categories of parents' education are at the normal range of values to the mean.

\section{Table 8}

Descriptive Statistics of the Students' Attitude Level by Parental Occupations

\begin{tabular}{lcccccccccc}
\hline \multirow{2}{*}{ Attitude Level } & \multicolumn{8}{c}{ Level of Parental Occupations } \\
& \multicolumn{1}{c}{ Agriculture } & \multicolumn{1}{c}{ Business } & \multicolumn{3}{c}{ Government Job Foreign Employ } & \multicolumn{2}{c}{ Others } \\
\cline { 2 - 11 } Value & M & SD & M & SD & M & SD & & M & SD \\
\cline { 2 - 11 } Enjoyment & 4.14 & 0.39 & 4.18 & 0.38 & 4.29 & 0.30 & 4.10 & 0.30 & 4.31 & 0.26 \\
Confidence & 3.96 & 0.66 & 4.06 & 0.67 & 4.09 & 0.60 & 3.84 & 0.84 & 3.93 & 0.68 \\
Motivation & 3.47 & 0.70 & 3.60 & 0.73 & 3.52 & 0.67 & 3.64 & 0.73 & 3.45 & 0.92 \\
Total & 3.68 & 0.80 & 3.64 & 0.81 & 3.69 & 0.74 & 3.61 & 0.91 & 3.60 & 0.99 \\
\hline
\end{tabular}

\section{Students' Attitude level by Place of Residence}

The mean score of the students' attitude level by their place of residence, the overall mean score of the rural area (3.89) found to be higher than the mean score of the urban area (3.77) as displayed in Table 9. Similarly, the factor wise mean score of all factors, selfconfidence (4.18), value (4.03), enjoyment (3.59), and motivation (3.76) was found higher in a rural area in comparison to the urban area. The greater mean scores of the rural location indicate that the students of the rural location had more positive attitudes towards mathematics than the students of the urban location. Similarly, the factor-wise standard deviations of the students' attitude by place of residence were found to be moderate and hence the data points of the category of the place of residence are at the normal range of values to the mean.

Table 9

Descriptive Statistics of the Students' Attitude Level by Place of Residence

\begin{tabular}{|c|c|c|c|c|}
\hline \multirow{3}{*}{ Attitude Levels } & \multicolumn{4}{|c|}{ Place of Residence } \\
\hline & \multicolumn{2}{|c|}{ Rural } & \multicolumn{2}{|c|}{ Urban } \\
\hline & $\bar{M}$ & $\mathrm{SD}$ & $\mathrm{M}$ & $\mathrm{SD}$ \\
\hline Self confidence & 4.18 & 0.37 & 4.17 & 0.37 \\
\hline Value & 4.03 & 0.65 & 3.92 & 0.69 \\
\hline Enjoyment & 3.59 & 0.67 & 3.41 & 0.74 \\
\hline Motivation & 3.76 & 0.75 & 3.59 & 0.84 \\
\hline Total & 3.89 & 0.61 & 3.77 & 0.66 \\
\hline
\end{tabular}

\section{Students' Attitude Level by Ecological Region}

The mean score of the students' attitude level with regard to ecological regions, the overall mean score of the Hill region (3.84) was found higher than the Mountain region (3.83) and the Terai region (3.79) as shown in Table 10. Gradually, students from the Terai and the Mountain region found to be a lower attitude towards mathematics respectively. Similarly, the 
factor wise attitude towards mathematics in the factors- confidence (4.41), value (4.04), and motivation (3.76) from the Hill region were found higher than the factors from the Mountain and the Terai regions. The mean score of the factor- engagement (3.64) from the Mountain region was found higher than the other regions. This indicates that the students from the Hill region are a more positive attitude towards mathematics. On the other hand, standard deviations of the factors from the Hill region- value (1.0), engagement (1.25), motivation (1.24); the Hill region- engagement (1.21) and motivation (1.1); the Terai region- value (1.02), engagement (1.81) and motivation (1.09) shows high standard deviation, that indicates the data points are spread out or scattered over a large range of values. Hence the data points of all categories of ecological regions are not in the uniform range of values to the mean. However, the students attitude level toward mathematics with respect to the ecological region is found to be at a positive attitude level.

Table 10

Descriptive Statistics of the Students' Attitude Level by Ecological Region

\begin{tabular}{|c|c|c|c|c|c|c|}
\hline \multicolumn{7}{|c|}{ Ecological Regions } \\
\hline \multirow[t]{2}{*}{ Attitude Levels } & \multicolumn{2}{|c|}{ Mountain Region } & \multicolumn{2}{|c|}{ Hill Region } & \multicolumn{2}{|c|}{ Terai Region } \\
\hline & $\bar{M}$ & SD & $\mathrm{M}$ & SD & $\mathrm{M}$ & SD \\
\hline Confidence & 4.12 & 0.81 & 4.21 & 0.71 & 4.16 & 0.70 \\
\hline Value & 3.89 & 1.0 & 4.04 & 0.9 & 3.98 & 1.02 \\
\hline Engagement & 3.64 & 1.25 & 3.36 & 1.21 & 3.45 & 1.81 \\
\hline Motivation & 3.68 & 1.24 & 3.76 & 1.1 & 3.58 & 1.09 \\
\hline Total & 3.83 & 1.07 & 3.84 & 0.98 & 3.79 & 1.15 \\
\hline
\end{tabular}

\section{Results of the Multiple Linear Regression Analysis}

The effect of demographic variables on students' attitudes towards mathematics, the test of assumptions for multiple linear regression analysis was performed and found well exists. In Table 11, the value of $\mathrm{R}$, the multiple correlation coefficients can be considered to be one measure of the quality of the prediction of the dependent variable. In this study, the value of $R$ $=0.234$ indicates a moderate prediction of students' attitudes towards mathematics. The $\mathrm{R}^{2}$ value, the coefficient of determination, indicates the quality of the relationship between the dependent and independent variables. The value of $\mathrm{R}^{2}=0.055$ explains that $5.5 \%$ of the total variability in the dependent variable (students' students' attitude towards mathematics) is contributed by the independent variables. The remaining $94.5 \%$ is to be accounted for by other factors that are not included in this study.

\section{Table 11}

Model Summary ${ }^{b}$

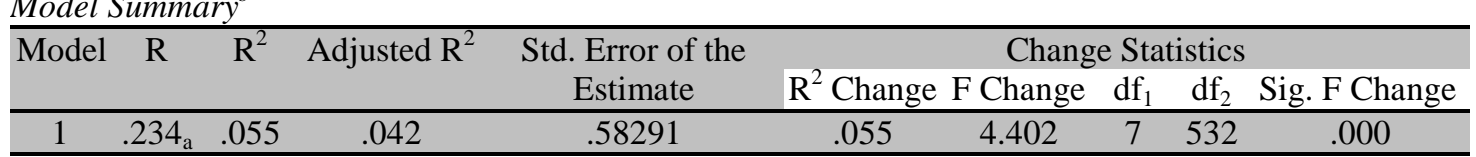

a. Predictors: (Constant), Ecological Region, Place of residence, Sex, Type of family, Parents occupation, Age, Parents education

b. Dependent Variable: Attitude towards mathematics 


\section{Estimated Regression Equation and Model Parameters}

The general form of the equation predicts the students' attitude towards mathematics.

$\mathrm{Y}=5.51+\left(-0.097 \times \mathrm{X}_{1}\right)+\left(0.028 \times \mathrm{X}_{2}\right)+\left(-0.129 \times \mathrm{X}_{3}\right)+\left(-0.137 \times \mathrm{X}_{4}\right)+\left(0.025 \times \mathrm{X}_{5}\right)+\left(0.005 \times \mathrm{X}_{6}\right)+$ $\left(0.027 \times \mathrm{X}_{7}\right),($ Table 12$)$.

Where,

$\mathrm{X}_{1}=$ Age

$X_{2}=$ Gender

$X_{3}=$ Place of residence

$X_{4}=$ Types of family
$X_{5}=$ Parents education

$X_{6}=$ Parents occupation

$X_{7}=$ Ecological region

$\mathrm{Y}=$ Predicted (Students attitude)

The unstandardized coefficients indicate to what degree the dependent variable varies from an independent variable when all other independent variables are held constant. The effect of the independent variables- age, gender, place of residence, types of family, parents' education, parents' occupation, and ecological region on dependent variable found to be -0.097 , $0.028,-0.129,-0.137,0.025,0.005$, and 0.027 respectively. This means that along with the increase in each independent variable, there is also an increase in the dependent variable. i.e. the unstandardized coefficient $\left(\mathrm{B}_{2}\right)$, age, is equal to -0.097 . This means that the increase along with the students' age, there is also an increase in students' attitudes towards mathematics by 0.097. In this case, when the students' age increases, then the students' attitudes towards mathematics tend to negative. Thus, when the values of the independent variable occur in negative then the relationship with the dependent variable tends to the opposite. In this study, the relationship of the independent variables $\mathrm{B}_{2}, \mathrm{~B}_{4}$, and $\mathrm{B}_{5}$ tends to negative. In short, from the beta value, it was found that the effect of independent variables on the dependent variable (students' attitude towards mathematics) contributes to a low level.

Similarly, the significance of the gradient shown by the $t$ scores also shows that only two independent variables, $t$ score of parents education, $t=0.664$ at $p=0.000$ and ecological region, $t=0.793$ at $p=0.000$ found to contribute significantly to the dependent variable. Thus, there is no so stronger association of the independent variables with the dependent variable (students' attitude towards mathematics).

Table 12

Regression Model Parameters on Students Attitude towards Mathematics

\begin{tabular}{lccccc}
\hline \multicolumn{1}{c}{ Model } & $\begin{array}{c}\text { Unstandardized } \\
\text { Coefficients }\end{array}$ & & $\begin{array}{c}\text { Standardized } \\
\text { Coefficients }\end{array}$ & $\mathrm{t}$ & Sig. \\
\hline & $\mathrm{B}$ & Std. Error & $\beta$ & & \\
\cline { 2 - 6 } 1. Constant & 5.511 & .388 & & 14.213 & .000 \\
2. Age & -.097 & .024 & -.176 & -4.010 & .000 \\
3. Gender & .028 & .052 & .023 & .540 & .589 \\
4. Place of residence & -.129 & .051 & -.108 & -2.548 & .011 \\
5. Type of family & -.137 & .055 & -.108 & -2.496 & .013 \\
6. Parents education & .025 & .038 & .031 & .664 & .507 \\
7. Parents occupation & .005 & .023 & .009 & .212 & .832 \\
8. Ecological Region & .027 & .034 & .036 & .793 & .428 \\
a. Dependent Variable: Student attitude towards mathematics \\
\hline
\end{tabular}




\section{Discussions}

The result of the secondary level students' attitude towards mathematics was found to be positive. The earlier finding of the study by Yasar (2016), that the attitudes of the secondary school students towards mathematics was found at a medium level, contradicts with this result. Bora and Ahmed (2018) found that the mean score of the students' attitude towards mathematics at secondary level was found below the average. However, the findings of the study (Mazana et al., 2019; Dowker, et al., 2019) corroborates the result that secondary level students attitude towards mathematics was found positive.

The result that the students having lower age group is found to be more positive attitude towards mathematics than higher age group students indicates that when the grade level of the students increase the students attitude towards mathematics decrease. The results of the studies examine the relationship between grade level and the attitude towards mathematics. Caliskan (2019) concluded that students' attitudes towards mathematics varied according to grade level, and attitude scores decreased as the grade level increased. As grade level increases, scores of the students' affective entry characteristics towards mathematics decrease. This shows that, when the age of the students increase then the students attitude towards mathematics decrease.

The result of the gender wise mean scores of the students' attitude towards mathematics revealed that there is no remarkable gender difference in students' attitude towards mathematics. The perception about gender difference in attitude towards mathematics is going to be changed (Yasar, 2016). Now a day, mathematics is being equally important for both boys and girls. As depicted by Caliskan, (2019) mathematical self-efficacy beliefs did not differ by gender. The result is aligned with the research finding of some previous researches (Farooq \& Shah, 2008; Yasar, 2016; Kaur, 2017; Karjanto, 2017; Dowker, et al., 2019; Batool et al., 2020; Fernández-Cézar et al., 2020; Zakaria, R. et al., (2020)). However the result contradicts that there were significant gender differences in students' attitudes towards learning mathematics in favor of male students (Dan'inna, 2016; Soleymani \& Rekabdar, 2016).

The result of the students' attitude towards mathematics with regard to their family type, the students from the joint family found comparatively more positive than the nuclear family. However, the students' attitude from the joint family towards the factor motivation was found neutral. The factor, motivation, from nuclear family was found positive. As depicted by Zhonglu and Zeqi (2018) family background variables affect students' attitudes towards learning.

The results that the students whose parents have higher education have more positive attitude towards mathematics align with many prior studies (Mbugua et al. (2012); Visser, Juan and Feza (2015). In the other hand, Akhtar (2012); and Dimakos, Tyrlis and Spyros (2012), emphasized about the mothers' educational levels that can influence more on students' 
performance and attitude than the educational level of the father. Thus, researchers found that higher educational level of parents had a significant positive impact on their child attitude towards mathematics.

The result that the students have more positive attitude towards mathematics whose parents have government employ than the students having their parents with other occupation. This result may concern with the income, guidance to their children and free time for study that enhance their children learning. The impact of the parents' careers on students' performance is most important (Barry, 2006). A study on high school student in Kenya found that, the cause of poor performance in mathematics is careers of the students' parents (Mbugua et al., 2012). This result is also supported by the Zhonglu and Zeqi (2018) that the family background variables affect students' attitudes towards learning. Akhtar (2012) found the effect of socio-economic variables on high school students' achievement in Pakistan that the mother's career had a positive effect on her children's achievement.

The result, that the students of the rural locations were found more positive attitudes towards mathematics than the students of the urban locations. However, the result of this study contradicts the findings conducted in India by Jayarani (2019), who found that the mean score of the urban students were higher than those of the rural location students. Moreover, Anjana (2018) reveals that both urban and rural secondary school students show almost similar attitudes towards mathematics. The results also support (Muthulakshmi \& Velikpan, 2014; Fernández-Cézar et al., 2020; Zakaria, R. et al., (2020)) as they explored no significant difference between mathematical attitude of rural and urban secondary school students. They claim the reason behind this may be that the students of urban and rural schools get equally proper environment, educational facilities and opportunities to develop their personality. Thus in this study, the reason may be the same as they claimed.

The result shows that the students from the Hill region were found to have comparatively more positive attitudes towards mathematics than the students of the Terai and the Mountain regions. However the mean differences of the students' attitude towards mathematics among the three regions are very low. According to Ntibi and Edoho (2017), the location influences on the academic sector are not the same. Some research has mentioned the impact of geographical region of students on their attitudes and performance. Yasar et al. (2014) studied the attitude of the students in Turkey toward mathematics and the effect of geographical region in their attitudes. They found that, the students from poor regions or (geographically remote) had more negative attitudes towards mathematics. Falch, Lujala and Strom (2013) investigated the impact of travel time between students' homes and their schools on their graduation. This also supports the result of the study that the students attitude from the Mountain region is comparatively low than the Hill and the Terai region. 
The socio-economic status of the family impacts on students' successes in mathematics (OECD, 2016). Similarly, the income of the household and higher earnings predicts the higher levels of educational attainment (Byrne and McCoy, 2017). In this study, the effect of the demographic variables age, gender, residence, types of family, parents' education, parent's occupation and the ecological region of pupils participating in the research has not been found the greater impact in their attitude towards mathematics learning. However, the effect of independent variables on dependent variable contributes at a low level. The independent variable, age have found opposite impact on students attitude towards mathematics. Likewise, the independent variables, parent's education and ecological region found to be contributing significantly to the dependent variable. The result shows that there is no such radical effect in students' attitudes towards mathematics due to the independent variables.

\section{Conclusions}

In this study, the mean score of the overall students' attitudes toward mathematics at grade IX reveal that the students had a positive attitude towards mathematics. Since students' attitude towards mathematics is a global issue, it is most important and equally essential for educators, teachers and parents to measure and determine the factors that form students' attitudes towards mathematics. This process of determining such factors provides the causes of the negative attitudes or help to find contributing factors that helps the educators to promote positive attitude towards mathematics and in turn to achieve higher achievement in mathematics. The effect of the demographic variables to the students' attitude towards mathematics under this study was found the nominal effects. The results of this study further demand the researcher to focus more on other variables that may have more impact on the students' attitude towards mathematics. The study concludes that the factors other than demographic, the instructional factors, and individual factors may be the causing factors that attribute to students' negative attitude towards mathematics. Thus, the teaching learning strategies that encourage learning, use of technologies in teaching that makes learning fun and motivational orientations should be utilized to promote positive attitude towards learning mathematics. Thus, the study recommends the concerned authority to go forward to find out the ways to enhance students' attitudes towards mathematics.

\section{Declaration of Conflicting Interests}

The authors declared that they had no conflicts of interest with respect to their authorship or the publication of this article. 


\section{References}

Adelson, J. L., \& McCoach, D. B. (2011). Development and psychometric properties of the Math and Me Survey: Measuring third through sixth graders' attitudes toward mathematics. Measurement and Evaluation in Counseling and Development, 44(4), 225-247. https://doi.org/10.1177/0748175611418522

Akhtar, Z. (2012). Socio-economic status factors effecting the students' achievement: a predictive study \& NBSP, International Journal of Social Sciences and Education, 2(1), 281-287.

Alacaci, C., \& Erbas, A. K. (2010).Unpacking the inequality among Turkish schools: Findings from PISA 2006.International Journal of Educational Development, 30(2), 182-192. http://dx.doi.org/10.1016/j.ijedudev.2009.03.006

Allport, G. W. (1935). Attitudes. In a handbook of social psychology. Clark University Press.

Allport, G. W. (1947). Scientific models and human morals. Psychological Review, 54(4), 182 192.

Anjana, (2018). Mathematical achievement in relation to problem solving ability, mathematical attitude \& anxiety of secondary school students [Unpublished PhD Dissertation]. Kurukshetra University, Kurukshetra.

Barry, J. (2006). The effect of socio-economic status on academic achievement. Available from Dissertations \& Theses Europe Full Text: Social Sciences.

Batool, T., Akhter, S., \& Kalsoom, T. (2020). Exploring gender differences in attitude towards mathematics at secondary level in Pakistan. Journal of Business and Social Review in Emerging Economies, 6(2), 587-596.

Bem, D. J. (1972). Self-perception theory. Advances in Experimental Social Psychology, 6, 162. https://doi.org/10.1016/S0065-2601(08)60024-6.

Bora, A., \& Ahmed, S. (2018). Secondary school students' attitude towards their learning geometry: a survey of Diphu town secondary schools. International Journal of Research and Analytical Reviews (IJRAR).

Byrne, D., \& Mccoy, S. (2017). Effectively maintained inequality in educational transitions in the Republic of Ireland. Am. Behav. Sci., 61, 49-73.

Caliskan, M. (2019). The examination of gender differences in affective entry characteristics towards mathematics. International Online Journal of Educational Sciences, 11 (5), 200-211.

Capuno, R., Necesario, R., Etcuban, J. O., Espina, R., Padillo, G., \& Manguilimotan, R. (2019). Attitudes, study habits, and academic performance of junior high school students in mathematics. International Electronic Journal of Mathematics Education, 14(3), 547561.

Dan'inna, A. A. (2016). Gender differences in secondary school students' attitudes towards learning mathematics and the resulting implications on their performance. Journal of Educational Research 6(1), 179-194.

Daskalogianni, K., \& Simpson, A. (2000). Towards a definition of attitude: the relationship between the affective and the cognitive in pre-university students. In T. Nakahara, \& 
M. Koyama (Eds.), Proceedings of the 24th Conference of the International Group for the Psychology of Mathematics Education, (pp. 217-224).

Di Martino, P. \& Zan, R. (2010). 'Me and maths': towards a definition of attitude grounded on students' narratives. J Math Teach Educ, 13, 27-48

Dimakos, G., Tyrlis, I., \& Spyros, F. (2012).Factors that influence students to do mathematics. The Teaching of Mathematics, 15(1), 43-54.

Dowker, A., Cheriton, O., Horton, R., \& Mark, W. (2019). Relationships between attitudes and performance in young children's mathematics. Educational Studies in Mathematics. doi:10.1007/s10649-019-9880-5

Eagly and Chaiken, (1993).The Psychology of Attitudes, Fort Worth, NY: Harcourt Brace Jovanovich.

Ernest, P. (2003). Setting the scene: the mathematical attitudes, beliefs and ability of students. Maths for Engineering and Sciences, 4-5.

Falch, T., Lujala, P., \& Strom, B. (2013).Geographical constraints and educational attainment. Regional Science and Urban Economics, 43(1), 164-176. doi:10.1016/j.regsciurbeco.2012.06.007

Farooq, M.S. \& Shah, S.Z., (2008).Students' Attitude towards mathematics. Pakistan Economic and Social Review, 46, 75-83.

Fernandez-Cezar, Raquel \& Garrido, Dunia \& Solano Pinto, Natalia. (2020). Do science, technology, engineering and mathematics (STEM) experimentation outreach programs affect attitudes towards mathematics and science? A Quasi-Experiment in Primary Education. 8. 1490.

Fishbein, M. \& Ajzen, I. (1975). Belief, attitude, intention and behavior: An introduction to theory and research. Reading, MA: Addison - Wesley.

Gay, L., Mills, G., \& Airasian, P. (2012). Educational research: Competencies for analysis and applications (10th ed.). Upper Saddle River, N.J.: Pearson Education, Inc.

Guy, G. Michael; Cornick, Jonathan; and Beckford, Ian (2015). More than math: on the affective domain in developmental mathematics. International Journal for the Scholarship of Teaching and Learning: 9 (2), Art 7. https://doi.org/10.20429/ijsotl.2015.090207

Haladyna, T., Shaughnessy, J., \& Shaughnessy, J. (1983).A causal analysis of attitude toward mathematics. Journal for Research in Mathematics Education, 14(1), 19-29.

Hart, L. E. (1989). Describing the affective domain: Saying what we mean. In D. B. McLeod \& V. M. Adams (Eds.), Affect and mathematical problem solving: A new perspective (pp. 37-45). New York, NY: Springer-Verlag.

Jayarani, R. N. (2019). Mental alertness, attitude towards mathematics and parental encouragement of higher secondary students in relation to their achievement in mathematics. Unpublished PhD Dissertation. Annamalai University.

Karjanto, N. (2017). Attitude toward mathematics among the students at Nazarbayev University Foundation Year Programme, International Journal of Mathematical Education in Science and Technology, 48(6), 849-

863, DOI: 10.1080/0020739X.2017.1285060 
Kaur, K. (2017). Gender differences in the attitude towards mathematics of ninth class adolescents of Chandigarh. Int. J. Res. Humanit. Soc. Sci., 5(3), 77-81.

Kunwar, R. (2020). Math mania: meaning, problems and ways of effective teaching and learning mathematics at basic level education in Nepal. International Journal of Science and Research (IJSR). (9)8, 1136-1141. DOI: 10.21275/SR20803202822

Kunwar, R. (2020). Mathematics laboratory in school level education in Nepal: An overview. International Journal of Science and Research (IJSR), 9(9), 327-334. DOI: 10.21275/SR20904111237

Kupari, P., \& Nissinen, K. (2013). Background factors behind mathematics achievement in Finnish education context: Explanatory models based on TIMSS 1999 and TIMSS 2011 data.

Li, Zhonglu, \& ZeqiQiu (2018). How does family background affect children's educational achievement? Evidence from Contemporary China. The Journal of Chinese Sociology, 5(1).

Mahato, R. Morgan \& C. Earnest, D. (2019).Early grade mathematics in Nepal: steps toward a stronger foundation. UNICEF, World Education. Ratopul, Kathmandu. http://nepal.worlded.org

Mazana, M. Y., Montero, C. S., \& Casmir, R. O. (2019).Investigating students' attitude towards learning mathematics. International Electronic Journal of Mathematics Education, 14(1), 207-231. https://doi.org/10.29333/iejme/3997

Mazana, M. Y., Montero, C. S., \& Casmir, R. O. (2020).Assessing students' performance in mathematics in Tanzania: the teacher's perspective. International Electronic Journal of Mathematics Education, 15(3), em0589. https://doi.org/10.29333/iejme/7994

Mbugua, Z., Kibet, K., Muthaa, G., \& Nkonke, G. (2012). Factors contributing to students' poor performance in mathematics at Kenya. American International Journal of Contemporary Research, 2(6), 87-91.

McLeod, D. (1992). Research on affect in mathematics education: a re-conceptualization. In D. Grows (Ed.), Handbook of research on mathematics teaching and learning (pp.575596). New York: McMillan Publishing Company.

Michelli, M. (2013).The relationship between attitudes and achievement in mathematics among fifth grade students.(Honors Thesis).

Mohamed, L., \& Waheed, H. (2011).Secondary students' attitude towards mathematics in a selected school of Maldives. International Journal of humanities and social science, l(15), 277-281.

Mohd, N., Mahmood, T. F. P. T., \& Ismail, M. N. (2011).Factors that influence students in mathematics achievement. International Journal of Academic Research, 3(3), 49-54.

Mutai, K. J. (2011). Attitudes towards learning and performance in mathematics among students in selected secondary schools in Bureti district, Kenya. Unpublished Masters Dissertation.

NASA (2019).Report on the national assessment of student achievement (Grade 5: Mathematics and Nepali) Sanothimi: Education Review Office.

Neale, D. (1969). The role of attitudes in learning mathematics. Arith Teach 16, 631-641 
Ntibi, J., \& Edoho, E. (2017). Influence of school location on students attitude towards mathematics and basic science. British Journal of Education, 5(10), 76-85.

Organisation for Economic Cooperation and Development (2016).Equations and Inequalities: Making Mathematics Accessible to All. Paris: OECD.

Peteros, E., Columna, D., Etcuban, J. O., Almerino, Jr., P., \& Almerino, J. G. (2019). Attitude and academic achievement of high school students in mathematics under the conditional cash transfer program. International Electronic Journal of Mathematics Education, 14(3), 583-597. https://doi.org/10.29333/iejme/5770

Ramanujam, R., Sachdev, P. L., \& Subramanian, R. (2007).Position paper on national focus group on teaching of mathematics.

Ratanasiripong, N. T., \& Chai, K. T. (2013). A concept analysis of attitude toward getting vaccinated against human Papillomavirus. Nursing Research and Practice, 2013, 15. doi:10.1155/2013/373805

Singha, K., Goswami, M., \& Bharali, R. (2012).Study of various problems faced by the students and teachers in learning \& teaching mathematics and their suggestive measures. International Journal of Advanced Research in Management and Social Sciences, 1(2), 195-201.

Soleymani, B. \& Rekabdar, G., (2016).Relation between math self-efficacy and mathematics achievement with control of math attitude. Applied Mathematics 6(1), 16-19. http://dx.doi.org/10.5923/j.am.20160601.03

Syyeda, F. (2016). Understanding attitudes towards mathematics (ATM) using a multimodal modal model: an exploratory case study with secondary school children in England. Cambridge Open-Review Educational Research e-Journal, 3, 32-62.

Tapia, M., \& Marsh, G. E. (2004).An instrument to measure mathematics attitudes. Academic Exchange Quarterly, 8(2), 16-21.

Visser, M., Juan, A., \& Feza, N. (2015).Home and school resources as predictors of mathematics performance in South Africa. South African Journal of Education, 35(1), $1-10$.

Yasar, M. (2016). High school students' attitudes towards mathematics. Eurasia Journal of Mathematics, Science \& Technology Education, 12(4), 931-945.

Yasar, M., Cermik, H., \& Guner, N. (2014). High school students' attitudes towards mathematics and factors affect their attitudes in turkey. Journal of Faculty of Educational Sciences, 47(2), 41-64.

Yunus, A. S. \& Ali, W. Z. W. (2009). Motivation in the learning of mathematics. European Journal of Social Sciences, 7(4), 92-100. 